\title{
French Health professionals' attitudes about patient empowerment in the cancer care pathway
}

\author{
Elise Verot*1, Véronique Régnier-Denois ${ }^{2}$, Dominique Feld ${ }^{2}$, Romain Rivoirard ${ }^{3}$, Franck Chauvin ${ }^{1}$ \\ ${ }^{1}$ Université de Lyon, Université Saint-Etienne, Centre Hygée, France \\ ${ }^{2}$ Institut de Cancérologie Lucien Neuwirth, Centre Hygée, France \\ ${ }^{3}$ Département d'oncologie médicale, Institut de Cancérologie Lucien Neuwirth, Centre Hygée, France
}

Received: April 17, 2019

DOI: $10.5430 / \mathrm{cns} . \mathrm{v} 7 \mathrm{n} 4 \mathrm{p} 41$
Accepted: September 24, $2019 \quad$ Online Published: September 30, 2019

URL: https://doi.org/10.5430/cns.v7n4p41

\begin{abstract}
Objective: France is experiencing a shift in health policy. The purpose of this article is to describe how cancer care health professionals define patient empowerment, describe modalities of care of the cancer patient treated by intravenous means and identify avenues for reflection on the specific challenges facing patient-centered care, from the perspective of changes in practices in the cancer care pathway.

Methods: 19 individual, semi-structured interviews with health professionals working in cancer care facilities were analyzed in a qualitative study, using the Theoretical Domain Framework linked to the COM-B model.

Results: The organization of care is governed by three factors. First of all, the cancer care system focuses on the strictly curative aspect of this disease. All devices lead to management centered on the pathology, and not on the patient as a whole. Secondly, the fact that the patient suffers from cancer modifies the attitudes and representations of caregivers towards the patient. Cancer introduces a relational bias in each of the stakeholders. Thirdly, the current organization of nursing care maintains paternalistic and prescriptive care in the cancer care pathway. Only new nursing jobs (coordinating nurses or pivot nurses) suggest the possibility of switching to patient-centered care. The analysis from TDF linked to the COM-B model shows that the strategy of implementing a new tool to measure the level of patient engagement, in routine nursing care, must focus on the reflective opportunity and motivation of the stakeholders.

Conclusions: Caregivers should be acculturated to patient empowerment. TDF linked to the COM-B model can make it possible to think about how to prepare and adapt this change in practice at several sites of cancer treatment. Training adapted to the context to familiarize current caregivers with this new form of care is currently being implemented. To succeed, acculturating current health care providers to this new form of care, while offering them a tool to objectively assess the level of patient empowerment would undoubtedly foster their involvement in supporting patient empowerment, while allowing them to evaluate the time required to integrate this type of care.
\end{abstract}

Key Words: Cancer care facilities, Patient empowerment, Person-centered care, Caregiver, Nursing, Qualitative study

\section{INTRODUCTION}

Initiatives by the National Health Strategy 2018-2022 and Ma santé ("My Health") 2022 $2^{[1,2]}$ have reoriented French health policy towards a person-centered approach, which seeks to "put the patient at the heart of care (...) with increased emphasis on experience and feedback (...); to provide the patient with access to information to allow him to play an active role in his own health". Innovative approaches

*Correspondence: Elise Verot; Email: eliseverot@gmail.com; Address: Université de Lyon, Université Saint-Etienne, Centre Hygée, HESPER EA7425, F-42023 Saint-Etienne, France. 
to strengthening the patient's empowerment would foster autonomy and participation. Students in the health sector must also be made aware of the patient's experience and possible issues involved in a relationship of care. ${ }^{[1]}$ For several years, the concept of patient empowerment has been a highly sought-after goal in the domain of chronic pathologies. The importance of patients' self-management of their long-term disease, particularly with cancer (categorized by the WHO as a chronic illness), including daily decision-making regarding their treatment, physical activity or diet, has been well-established. ${ }^{[3,4]}$ The number of patients treated on an outpatient basis is increasing, while the length of hospitalization stays is decreasing, leading to more complex pathways of care. ${ }^{[5]}$ Improving the "performance" of care requires a gradual empowerment of patients. ${ }^{[6]}$ This need to evolve towards a more general vision of patient care in oncology was underlined by the first results from Unicancer's Patient Expectations Observatory ${ }^{[7]}$ and, more recently, by the Cancer Plan III 2014-2019, described in objectives 2 and 7. ${ }^{[5]}$ The question of today's capacity of health professionals to support patient empowerment in the course of cancer care arises, given the new health policy orientations in France. ${ }^{[1]}$ Indeed, as seen above, the government strongly encourages health professionals to adopt the model of support for patient empowerment. ${ }^{[1]}$

This article aims to:

1. Describe how cancer care health professionals define patient empowerment.

2. Describe modalities of care of the cancer patient treated by intravenous means.

3. Identify avenues for reflection on the specific challenges facing patient-centered care, from the perspective of changes in practices in the cancer care pathway.

\section{MethodS}

This research is part of an interventional nursing research study, which adopts an implementation research method. ${ }^{[8]}$

This involves deploying a tool to measure the level of patients' activation in routine practice by a nurse, at several participating sites. The nurses involved are committed to implementing ad hoc management strategies to support patient empowerment.

To better understand the social representations of the professionals, a multi-centric qualitative study was conducted in three cancer treatment centers. The sites chosen feature cancer care facilities in a department of the largest region of France and represent three categories: the public university establishment, the specialist public establishment and the private establishment.

\subsection{Characteristics of the sample}

\subsubsection{Source and method of recruitment}

The health professionals met were all nominated by the site's investigating physician as they were directly involved in the care of patients treated for cancer by intravenous means. They also shared contact details of the department executives, enabling us to arrange appointments.

\subsubsection{Inclusion and exclusion criteria}

The inclusion criterion consisted of an agreement by the professional to the principle of participation in collecting data. Consent was given by email or verbally during the appointment arrangement process. The exclusion criterion was a refusal to take part in the study. All those designated have agreed to participate and have been met.

\subsection{Semi-structured interviews}

\subsubsection{Using the Theoretical Domain Framework (TDF)}

The TDF was developed by $\mathrm{S}$. Michie et al. to understand practices of health professionals and identify elements of practices to target for the implementation of new recommendations. ${ }^{[9]}$ It helps for implementing evidence-based practice. ${ }^{[10]}$ According to Atkins et al., implementing new practices and/or changing existing practices in organizations, services and systems require changes in individual and collective behavior. ${ }^{[1]}$ They also explain that this framework has been used primarily in healthcare settings for exploring factors influencing clinical behaviors to design implementation interventions: to identify barriers and facilitators to change. ${ }^{[11-13]}$ Alan Glasper and Colin Rees explain that each domain of the TDF represent behavioral determinant. These determinants are mediators of behavior change. ${ }^{[14]}$ The TDF was composed of 12 theoretical domains outlined in an interview guide. The 12 domains are (1) knowledge, (2) skills, (3) social/professional role and identity, (4) beliefs about capabilities, (5) beliefs about consequences, (6) motivation and goals, (7) memory, attention and decision processes, (8) environmental context and resources, (9) social influences, (10) emotion regulation, (11) behavioral regulation, and (12) nature of the behavior. ${ }^{[10]}$ Employing this tool to frame the interview guide helped identify elements that either hindered or facilitated the implementation of new modes of care in everyday practice. Michie and her team have produced a series of questions based on each of the 12 TDF domains. These questions can be used to identify and understand evidence based practice implementation issues, during the semi-structured interviews. ${ }^{[10]}$ In order to utilize it, we have realized a double translation of these questions. Then, a test phase with 5 persons of differing profiles to ensure good understanding in French was done. It was presented to 4 health professionals to confirm its relevance to the target audience. 


\subsubsection{The interview guide}

To construct the interview guide, we followed recommendations produced by Atkins et al. in their "Guide to using the Theoretical Domains Framework of behavior change to investigate implementation problems". ${ }^{[11]}$ They advocate an open question for each theoretical domain, followed by different follow-up questions. So, we used the series of questions we have translated in French. The form and content of the interview guide were validated by a socio-anthropologist of health with a doctoral degree, specialized in the cancer research field. As recommended by Atkins et al., the guide began with a general open question, "Please tell us about the care of the patient being treated for cancer by intravenous means". Then, an open question was asked to address each domain, with follow-up questions. For example, regarding the domain 3 (social/professional role and identity), the open question was: "Which professionals shall be involved in $\mathrm{x}$ ?". And the follow-up question was: "Is doing $\mathrm{x}$ compatible or in conflict with professional standards/identity?" Through the responses, we sought to understand the definition of patient empowerment in oncology by health professionals. The second object was to collect their representations about patients' empowerment (its theoretical delimitations, its associated values, implementation possibilities and difficulties) and its relationship with the current practices of health professionals, on the cancer care pathway.

For the study itself, 19 semi-structured interviews were conducted in the 3 facilities mentioned above, both in general hospital departments and day-hospitals in oncology. The interview guide proved relevant for all types of professionals involved in the cancer care pathway. Each interview was conducted in a calm environment, held in an office, face to face, with enough time to enable the professional to give his undivided attention. The sample consisted of physicians ( $\mathrm{n}=$ $4)$, nurses $(n=8)$, assistant nurses $(n=2)$ and other health professionals involved in the care of patients undergoing cancer treatment $(n=5: 1$ psychologist, 1 dietitian, 2 medical secretary, 1clinical research assistant). The sample included 15 women and 4 men.

The advantage of using this tool is that it proves to be effective in collecting complete representations within a time acceptable to practising health professionals. ${ }^{[15]}$ The TDF is helpful when researchers have limited time with participants to conduct interviews. Indeed, the time that caregivers can give a research team for qualitative interviews is an important factor to consider.

\subsection{Data collection phase}

The collection took place from May to June of 2017.

Published by Sciedu Press
The semi-structured interviews were conducted by the first author, who holds a Master of Science in Nursing Studies and is currently a $\mathrm{PhD}$ candidate, trained in qualitative research. The framework in which the data collection took place was explained to each participant: in order to ensure freedom of speech, the participants were assured protection of data, anonymization, and confidentiality with respect to their hierarchy.

All 19 interviews were recorded in their entirety on a digital audio recorder. Each interview was transcribed wordfor-word in verbatim form and anonymized. The average duration of each interview was 24 minutes.

\subsection{Qualitative data analysis}

Following the "Guide to using the Theoretical Domains Framework of behavior change to investigate implementation problems", data can be analyzed deductively, using the TDF to generate the framework for a content analysis and, inductively, generating themes that can then be considered in relation to domains. ${ }^{[11,16]}$

Two analyses were performed with the same data. The first analyze was a deductive one. It is reading participants' responses in the transcript, considering their relevance to the definitions of the domains and then attributing them to one or more domains. This in order to use the COM-B model and the Behavior Change Wheel to adapt the implementation to the context. The second analysis was an inductive one. It consists of analyzing the same data to find out more about the representations of the professionals interviewed. This is a thematic analysis. 3 themes were generated and 9 sub-themes. Nvivo 11 pro (QSR International) software was used to conduct both analysis. The first author analyzed the data. Once completed, the analysis were deeply discussed with the second author, socio-anthropologist of health, Phd, specialized in the cancer research field. The participants did not provide any feedback on the results.

\subsection{Ethical considerations}

The study protocol was approved by the Patient Protection Committee of Ile de France VIII (N ID RCB: 2017-A0023548). All participants were given written and verbal information about the study and gave informed consent to participate. The COREQ checklist guided the preparation of this manuscript. ${ }^{[17]}$

\section{Results}

The 3 main categories used to present the results consist of system-related, patient-related and nursing managementrelated factors. These 3 factors constitute the themes found in our analysis and comprise 9 sub-themes (see Table 1). 
Table 1. Overviews of the cancer care nursing providers' experience of managing patients on the cancer care pathway

\begin{tabular}{|c|c|c|c|}
\hline \multirow{2}{*}{ Theme } & \multicolumn{3}{|c|}{ Care of the patient receiving intravenous treatment in oncology } \\
\hline & Health system related factors & Patient related factors & Nursing management related factors \\
\hline Sub-theme & $\begin{array}{l}\text { - } 100 \% \text { cancer-centered care } \\
\text { - An environment conducive to } \\
\text { developing a passive patient } \\
\text { attitude } \\
\text { - The doctor and paramedical } \\
\text { caregivers induce passive } \\
\text { behavior in the patient }\end{array}$ & $\begin{array}{l}\text { - Vulnerability related to social } \\
\text { representations of cancer } \\
\text { - Information and adherence } \\
\text { perceived as key factors of } \\
\text { patient empowerment } \\
\text { - The myth of the docile patient }\end{array}$ & $\begin{array}{l}\text { - Incompatibility with current modes } \\
\text { of care } \\
\text { - Insufficient availability of } \\
\text { caregivers for care other than } \\
\text { technical care and consultation } \\
\text { - Delegation of part of the care to } \\
\text { coordinating nurses (pivot nurses) }\end{array}$ \\
\hline
\end{tabular}

\subsection{General observations}

The exploration of possibilities of the patient as an actor and his empowerment is not central to strategies of care. For half of the sample, empowerment is seen as a synonym for the patient's autonomy, embodied by his acts in daily life or usage of a medical measure. Those who imagine care that focuses on support for the patient's empowerment remain highly skeptical about the added value such a strategy can produce.

"I still have kind of a hard time seeing concretely what benefit it's actually going to bring." (Paramedical caregiver)

For the doctors, although the concept is perceived as innovative and interesting, support for patient empowerment seems to be incompatible with their rounds, unless its usefulness can be demonstrated.

"If it improves quality, we could be persuaded to do it, but during our rounds, without proof of utility, if it's just out of curiosity, honestly we have other things to do." (Medical caregiver)

\subsection{Health system related factors}

The cancer care system focuses on the strictly curative aspect of this disease. All devices lead to management centered on the pathology, and not on the patient as a whole.

\subsubsection{0\% cancer-centered care}

In all cases, care was described as $100 \%$ cancer-centered, with a focus placed exclusively on the disease and its treatment. Caregivers explain that what may be a priority for the patient is not necessarily a goal for the health care team.

"In any case, it may not be a priority for us in terms of care, but it can be something considered a priority for the patient." (Paramedical caregiver)

The characteristics of the patient are collected by admissions questionnaires or directives. When problems are identified, the paramedical caregivers relay information to seek practical solutions before evaluating subsequent actions to put into place. Collecting patient data and keeping a nursing file are essential tasks done by the paramedical staff. The collected elements are necessary to execute technical acts and to bring pragmatic solutions that guarantee good quality of care. Data collection must be as accurate as possible to achieve the goals of care. Thus, it is the caregiver who acts, not the patient.

"Time goes by fast, but also, (...) since we don't have much time, we must be very, very precise and targeted, to do what's necessary to best treat the patient." (Paramedical caregiver)

\subsubsection{An environment conducive to a passive patient atti- tude}

Upon arrival, the patient is encouraged to become adjusted to the department's pace, requirements and limitations.

"The patient sometimes has to adapt to us, in terms of everything we have to do in a department, that's when there's a rush; (...) I find that the patient is really left aside." (Paramedical caregiver)

From the outset, the hospitalized patient is placed in a relationship of dependency on the professionals who ensure his care.

"The hospitalized patient is already more in a relationship of dependency." (Other health professional)

The caregiver relies on his intuition and instincts to assess the level of the psychological state of a patient. When he perceives a fragility, he almost automatically requests care from the onco-psychology support department. The patient himself seldom requests this type of care.

"The request for psychological support always, or almost always, emanates from the caregiver, the medical staff. Very rarely, exceptionally, from the patient." (Other health professional) 


\subsubsection{The doctor and paramedical caregivers induce pas- sive behavior in the patient}

The doctor places the patient in a position where he does not really have a choice as to how he can manage his illness. Patient empowerment becomes synonymous with disruption of medical practices.

"It would mean that you are going to change the world of doctors! (...) 'So sir, you're going to do your chemo or your chemo, right? Do you agree?' 'Well, yes I agree'. Because they don't have a choice!" (Other health professional)

He greatly influences the patient to accept supportive care or sites of treatment for the disease. The patient accepts because he does not question the decisions of the prescriber of the modalities of his care.

“There's no choice, we don't even let people choose the facility where they are going to get treatment." (Paramedical caregiver)

The paramedical professionals explain that the influence of the doctor is crucial for continuation of care. By initiating the patient to adopt a passive attitude during the first consultation, he conditions the patient to continue the same attitude throughout the entire pathway of care. At his request, appointments and other events can be managed and organized by the secretarial staff. The patient does not need to become involved in the care of his illness.

"I think they're not active (...) In fact, we do everything to our patients (...) they're not involved in their care of the disease." (Other health professional)

In addition, the caregiver knows what the patient needs. $\mathrm{He}$ thinks the patient needs guidance and nurturing. The positive expressions of gratitude from the patient at the end of care validate the value of a nurturing attitude.

"They need guidance and they need to be nurtured (...) so, when they leave, well, I am thanked to some extent." (Paramedical caregiver)

The care of women by female health caregivers during chemotherapy, especially when alopecia occurs, exemplifies all the more this maternal attitude. The caregivers invariably base their care on reassuring these patients and helping them "live with" the hair loss.

Finally, the patient appears unwilling to become interested in his treatment and its modalities. For paramedics, it is normal that the patient is non pro-active during his hospital stay. They explain that the patient voluntarily lets himself be guided by the caregivers. As a result, the latter do not consider modifying their disposition and practices; they cannot imagine what good it would do to entertain the idea of the patient playing an active role in his care.

"Because they let themselves be guided, because the names of the products don't interest them, because chemo is poison, because I don't see what we could replace it with (...) I don't see what good it would do to know if they are not (...) In fact, I find it normal that they are not active participants in their treatment." (Paramedical caregiver)

\subsection{Patient related factors}

The fact that the patient suffers from cancer modifies the attitudes and representations of caregivers towards the patient. Cancer introduces a relational bias in each of the stakeholders.

\subsubsection{Vulnerability related to social representations of cancer}

Doctors see patients as being in a state of psychological shock and assume they would therefore be unable to commit to being empowered.

"We must not, whatever the escalation, people don't have the brain capacity for all that." (Oncologist)

Moreover, if they were to take part in an assessment of the patient's empowerment capacity, it would be difficult to determine at what moment in the care pathway it should be implemented.

"It's a big shock, there are some who are stunned, there is time for caregiver support, so then, where do we come in?" (Oncologist)

For paramedical caregivers, the patient is seen as exhausted due to his cancerous disease. The concept of cancer naturally leads these caregivers to feel obliged to take special care of and support patients perceived as vulnerable, and to act on their behalf.

"We take special care of people, they are cancer patients here, that's cancer for you." (Paramedical caregiver)

Time spent in the hospital for a hospitalization or day-patient treatment is an opportunity for the patient to breathe. The moment is perceived by the caregiver as a suspension from everyday life, leaving things up to take over the care of the disease and all related aspects so the patient can take a "break" from his cancer and its ills.

"It's as if they were better for one day; they let themselves go, but as soon as they leave, they must have their next appointment in mind, do the blood test at the right time (...)." (Paramedical caregiver)

In all situations where a therapeutic solution exists, the caregiver does his utmost to convince the patient to adhere to the 
medical instructions and strategies as planned. Paramedical caregivers explain that they feel helpless when no further treatment is possible in cases of advanced cancer. Only at this stage do they agree to leave the choice up to the patient to decide how he wishes to fit it into his continuum of care, since they remain powerless.

"We come to a stage where we have nothing left to offer, where there is no effective treatment, so in this case, we can let the patient decide (...) but when faced with a long-term illness, we can treat it, we don't let the patient (...) we can still try to convince him, we can try to do things so that he accepts." (Paramedical caregiver)

The difficulty of no longer being able to help the patient seems directly akin to the mission of the caregiver who fights for the patient in his battle against cancer. The caregiver encounters a tough situation when a patient makes a choice that seems like a renunciation, which reinforces the vulnerability of the patient.

“It's hard at times, because we're not here to give up, but on the contrary, to help them as best as we can, but when they don't want it, they don't want it." (Paramedical caregiver)

The caregiver involved in overall care means thinking about everything and planning every eventuality for the patient, from the hospital to the patient's home.

"It begins here, when he arrives in the department, until the moment he returns home; we are also concerned about the care at home (...) If we need to send people, meaning caregivers, for the family, if the patient needs to see a psychiatrist or needs help with pain, here, you have to admit, we are well-equipped in terms of care support." (Paramedical caregiver)

The help or solution proposed to the patient is pragmatic and nearly instantaneous, between technical care and implementation. It takes on an even greater significance in a day-hospital, since the patient remains for just a few hours. From the moment he checks in, time is spent bringing solutions to the patient. The notion of help through concrete action is omnipresent with the paramedical caregiver.

"You have to understand certain moments very quickly too and try to help as soon as possible.” (Paramedical caregiver)

\subsubsection{Information and adherence perceived as key factors of patient empowerment}

The pro-active patient, committed to his continuum of care, is a patient who must be well-informed by the staff, who is docile and conciliatory. The notion of the patient-actor is intrinsically linked to the amount of information delivered by the paramedical personnel. Information is provided through information leaflets, including the range of available supportive treatment the patient has access to. At no point is the patient allowed to question the team about the existing processes. Everything is given to the patient as soon as he is on the cancer care pathway.

"It can allow the patient to be a little more involved in these steps, that's for sure (...) from the beginning of the illness too, we give them a brochure of information in the notification stage, where all the supportive care is listed." (Paramedical caregiver)

The commitment of the patient is perceived by caregivers as actually accepting the care, accepting to receive treatment and to follow the recommendations of the team. For caregivers, patient empowerment goes hand-in-hand with adhering to the program. Patients who do not follow the recommendations of the health professional cast a certain doubt on the ability of that professional to execute their care effectively, which leads to a difficult situation.

"The patient, in any case, must be an actor to some extent (...) because, if he's not, we realize it's difficult to implement." (Other health professional)

"People feel completely involved, I mean, they are very willing, they are going to do everything we ask of them!" (Paramedical caregiver)

\subsubsection{The myth of the docile patient}

A distinction is quickly made between the docile, conciliatory patient and the patient who does not conform to the caregiver/care-recipient relationship. In this case, the caregiver is inadequate because he cannot mobilize the patient as he sees fit. The patient is then deemed incapable of becoming an actor.

The caregiver/care-recipient relationship is asymmetrical, with the caregiver in a superior position. The patient, inferior, does not dare express himself freely in front of the caregiver. Due to his fear, he will be labelled a "good patient" (docile) and/or will choose to hide what seems complicated or problematic to him.

"They want to respond because they are afraid of, well... they want to be good patients." (Paramedical caregiver)

One observes that the patient is generally reluctant to speak freely about his perceptions when questioned by a caregiver or when a caregiver is in close proximity.

"The patient will have a harder time saying negative things if there is a caregiver nearby.” (Medical caregiver)

ISSN 2324-7940 E-ISSN 2324-7959 


\subsection{Nursing management related factors}

The current organization of nursing care maintains paternalistic and prescriptive care in the cancer care pathway. Only new nursing jobs (coordinating nurses or pivot nurses) suggest the possibility of switching to patient-centered care.

\subsubsection{Incompatibility with current modes of care}

Paramedical health executives acknowledge that mindsets are changing, but given the current system, with its structure and organization, suggesting changes in practice are impossible to implement. The person-centered approach with support for patient empowerment is in opposition to current organizations of services and nursing care. Team leaders are powerless in their efforts to integrate and construct this new approach to care.

"Things are changing (...) How can we implement them? What form will it take? I mean, it takes time because, in fact, to perform an educational assessment with the patient's input takes 45 minutes to an hour; it involves all that, how can we work it into our current schedules?" (Health executive)

We are faced with two paradigms: considering the patient overall, fulfilling his individual demands, or persisting in keeping today's practices, based on a prescriptive approach to care and treatment. The lack of a concrete solution on-site, able to meld the two opposing approaches, places caregivers in a difficult position.

"We're always juggling between the identified needs of the patient and our organization and suddenly we are mixing everything - it's not always easy, if you know what I mean!' (Health executive)

\subsubsection{Insufficient availability of caregivers for treatment other than technical care and consultation}

As of today, the patient-centered approach is still perceived as a foreign concept of care.

Care is defined by concrete actions related to the administration of intravenous chemotherapy treatment. In order to be able to potentially introduce this new mode of a caregiver/care-recipient relationship, it has been suggested that organizations set aside time specifically for listening to the patient.

"I think it's something that's part of our daily lives, but is difficult to implement (...) I mean, how should I put it? Strictly speaking, it's not part of care." (Paramedical caregiver)

For doctors, supporting patient empowerment requires devoting time they cannot afford. They discuss a possibility of implementing it during a study (for a limited duration, involving only certain patients) but not in everyday practice.

This notion of lack of time is crucial and central to care for Published by Sciedu Press all the professionals we met. They mentioned the time necessary for each patient as a factor that places limits on their support for empowerment. Helping the patient to achieve more empowerment requires a modification of the initial approach in relation to the patient, a non-prescriptive and open exchange with an available interlocutor.

"To be able to ask such questions, but on the other hand concretely, yes, it's going to be time, because, precisely when one raises these kinds of questions, people have a tendency to unload a bit." (Paramedical caregiver)

The workload in a Day Hospital or traditional hospitalization department is cited as being responsible for an alteration in the quality of care of current patients.

"We have a lot of work, so to administer care to a patient properly takes time." (Paramedical caregiver)

\subsubsection{A delegation of part of the care to coordinating nurses (IDEC) or pivot nurses in oncology (IPO)}

The holistic treatment of the patient is purposely left to the coordinating or pivot nurses, who provide long-term follow-up of the patient. Their role differs from traditional caregivers who work in situations of hospitalization or dayhospitals. These coordinating staff members serve as direct points of reference for the patient. The "traditional" medical and paramedical body delegates this mode of care to this new category of caregiver.

"They see the doctor and then they are referred to a pivot nurse, who for us here, is their point of reference, their go-to person." (Paramedical caregiver)

Coordinating nurses play an essential role; they appear to be the only ones who invest in long-term care with allotted time to spend interacting with the patient. Hospital nurses feel a redundancy with the care provided by pivot nurses, in terms of information to be delivered to the patient. However, as previously mentioned, they still relay informative content, since it is part of their role. Finally, at the two sites that do not have this type of staff, paramedical caregivers believe this service is sorely lacking. The presence of a coordinating nurse relieves the paramedical aide staff of this relational aspect of care.

"They often call the service and we are the ones who manage everything, whereas if there was a coordinating nurse, she would be the person taking care of the patient; as for us, we move fast!" (Paramedical caregiver)

The pivot nurses demonstrate the care focused on actively listening to the patient, a relationship they can gradually build during time spent with the patient. We notice that a change in practice was adopted: the habit of the caregiver to express 
himself in place of the patient no longer occurred. This relational aspect is an element that differs from traditional care discussed above.

"Not getting into the habit of speaking in their place, or I mean, when they can express themselves; it's also a way of helping and supporting them; we're kind of there as a companion." (Coordinating nurse)

Nevertheless, the organization of care is limited by the time factor and the obligation to include a maximum of patients on a daily basis.

\section{Discussion}

The use of TDF has made it possible to identify 3 major obstacles to the implementation of new nursing practices, aimed at supporting the empowerment of patients treated for cancer. ${ }^{[12]}$ These domains are D5 Beliefs about consequences, D8 Environmental context and resources, D9 social influences. The 12 domains of the TDF can be based on 3 core components: capability, opportunity and motivation (the COM-B model). Several research teams have used TDF linked to the COM-B model to understand behaviors related to implementation problems, particularly in the area of health. ${ }^{[12]}$

The COM-B model stipulates that human behavior (B) results from the interaction between personal physical and psychological abilities (C), to exploit social and environmental opportunities $(\mathrm{O})$ through reflective and automatic motivation (M). ${ }^{[18]}$ By linking these 3 domains of TDF to the COM-B model, we observe that Domains 8 (Environmental Context and Resources) and 9 (Social influences) are directly linked to social and physical Opportunity and that Domain 5 (Beliefs about consequences) is directly related to reflective motivation.

\subsection{Domaine 8: Environmental context and resources}

\subsubsection{Assertion of incompatibility between the organiza-} tion of current care and the patient-centered approach with support for empowerment

These results highlight the difficulties today for French caregiver teams in oncology to be able to adjust to the orientations of the new health policy. Putting the patient back at the center of care and supporting his empowerment is not a feasible option for today's teams.

According to the ministerial recommendation, placing an emphasis on the notion of "putting the patient back at the heart of care" means that the patient has been displaced. The suggestion to "consider more closely his life and the feedback on his experiences" proves it is imperative today to engage in a different relationship with the patient. In the field, this implies a necessary modification of care practices among professional caregivers, to enable the patient to become an actor in his health and to place himself at the heart of the care. The collection of patient data, illustrated by the verbatim statements, should not be utilized merely to meet the caregivers' goals, but rather, to serve as a means to connect authentically with the patient to establish a relationship of trust and equality. Likewise, overall patient care should no longer be limited to collecting required indicators for caregivers, but also to consider the patient's experiences to construct a relevant and individualized relationship with him. Several studies have demonstrated the caregiver's role in the patient's empowerment process, especially placing an emphasis on interpersonal skills, based on motivational interview techniques or other relational communication techniques. ${ }^{[19-22]}$ Yet, as the findings show, relational care, the guarantor of a symmetrical caregiver/care-recipient relationship, is delegated today to the coordinating nurses (or pivot nurses) in the course of oncology care. Lemay ${ }^{[23]}$ explains that patient empowerment should be understood as a process of changing the relations of power, which results in a two-way modification of those with little or no power and those who possess power and authority in different systems. Sands and Wehmeyer complement one another by insisting that this requires a more balanced adjustment of the forces involved. ${ }^{[19]}$

\section{A strong time constraint limiting the availability of care- givers}

Our research illustrates the difficulty of physicians to imagine themselves in a participative mode of the patient due to the extent of their densely condensed appointments within a limited timeframe. The same applies to paramedical aides who are focused on technical care, for the sake of optimizing and controlling the time factor. This implicit adaptation of practices to requirements of the care system strengthens the resistance of health professionals to orient their care differently. Olivia Gross ${ }^{[24]}$ corroborates this concept by citing the same arguments of opposition to the paradigm shift as those mentioned by the professionals encountered in this study. The shift toward technical care was at the expense of relational care, for which the time factor is difficult to quantify beforehand. The verbatims testify to the fact that these interpersonal skills of the caregiver are no longer regarded today as care specific to oncology when it comes to nursing care. The results show that caregivers are aware that they work based on their priorities, with an approach centered on the disease and the goals of care. To get to know the patient and have the feeling of working in a more general approach, they remain in a directive relationship, by collecting patient data using a somewhat impartial questionnaire, with 
pre-determined answers. This allows them to master the time factor, which is an essential variable in their perception of the effectiveness of their care.

However, the wishes expressed by patients are in line with the reorientation of health policy towards the user-centered approach.

Indeed, for the first time in the world, a scientific study (the Compare cohort) brought together 1,613 French patients to ask them about areas for improving care in the context of chronic diseases. Most of the areas for improvement proposed by patients concerned the quality of exchanges between doctors and patients, informing patients about their care and adapting the patient's treatment according to their preferences and context. In particular, they stressed the importance of interactions between the patient and the medical and paramedical teams. ${ }^{[25]}$

We therefore understand that it is becoming necessary to implement new practices in nursing care.

\subsubsection{Strong ministerial incentives to the empowerment model}

The implementation of the North American model in France with IDEC/IPO in oncology is a factor of disparate results regarding empowerment support.

In healthcare facilities that provide care for cancer patients, the therapeutic medical department is run by personnel. The time for consultation and listening remain rather limited and is insufficient to support real empowerment of the patient. Oncologists have a paramedical team to rely on to guide the patient on a pathway of care. The medical dimension can thus be perceived as relatively fixed: the patient's empowerment is modulated in large part by the paramedical aide team set up within the establishment treating the cancer. These teams are composed of different and complementary specialty professionals, including coordinating nurses or pivot nurses. However, their presence varies according to the specific establishment and its size, as we noted in our study, with an absence of a coordinating nurse (or pivot nurse) in 2 out of 3 centers. Thus, the implementation of different care pathways in terms of paramedical personnel results in varying levels of care and, consequently, disparate levels of patient empowerment.

\subsection{Domaine 9: Social influences A system unsuitable for this model}

It is important to remember that the primary purpose of the hospital is not well-suited to the care of chronicity. The management of the acute phase is historically the defining characteristic of the hospital, making it a challenge to change the practices and contexts of care of chronic illness, particularly in oncology. As pointed out by Longtin et al., despite certain functional experiences of integrating patients, the reality is that caregivers tend to get locked into their traditional roles and have difficulty transferring power to patients. ${ }^{[26]}$

\subsection{Domaine 5: Beliefs about consequences}

The need to broaden the "at a minimum" concept of empowerment, a factor limiting the loss of control of the caregiver

This study shows that health professionals diminish the notion of empowerment in favor of therapeutic adherence. The patient-actor complies with the care provided by the team, while obediently carrying out prescriptions and recommendations. The "patient-actor" concept is also conditioned by the delivery of health information to the patient. This finding mirrors the results of Mougeot et al. which illustrate that, most often, patient participation does not extend beyond the information and consultation stage. ${ }^{[27]}$

However, according to Ninacs, empowerment requires a combination of the following capacities: participation, know-how, self-esteem and critical thinking. ${ }^{[28]}$ The notion of empowerment as synonymous with adherence, as perceived by the caregivers interviewed, associated with the idea of the patient as actor, runs counter to this definition of support for empowerment. The health professionals interviewed clearly admit that their modalities of care, which place the patient in a passive role, do not leave them room to freely exercise these four abilities. Consequentially, the posture of these professionals does not allow the patient to take part in an empowerment process.

In addition, caregivers have the perception that patients treated in oncology have a relatively limited freedom of choice, since they are strongly influenced by the doctor or nurse to accept a strategy of care or treatment. These results correspond to explications by Pomey et al. ${ }^{[29]}$ on shared decision-making or therapeutic education (purportedly in support of patient empowerment) that can help strengthen the caregiver's control over patients.

This qualitative research also exemplifies how care in oncology is heavily influenced by the corrective reflex of the caregiver. Social representations of professionals in dealing with cancer only serve to accentuate the point. Such a stance is the result of training, where the balance of the caregiver/carerecipient relationship is rarely discussed, where expertise remains the sole property of the medical and paramedical body. Miller and Rollnick ${ }^{[30]}$ explain that the caregiver naturally wants to help the patient. He thus provides remedies for what seems harmful through advice and warnings to help the patient modify his behavior in order to improve his condition, 
get better treatment results and gain a better perception of quality of life. When the patient goes off-track or changes his stance, for example, renouncing the illness, the caregivers redouble their efforts to make him stay on-course in order to achieve the objectives set by the staff. Such an attitude challenges the acceptance of the loss of control, both for the patients and the caregivers. Lemay ${ }^{[23]}$ agrees, stating that the main dilemma of those who intervene is to encourage persons to regain control of their lives, while continuing, despite these intentions, to control certain aspects of it. When health professionals adhere to the philosophy of patient empowerment, they often experience a conflict between their (prescriptive) caregiving role and the patients' desire to be proactive in their continuum of care. One can compare this approach to Barello's analysis, which explains that professional actors may be limited in maintaining the patient's empowerment and feel challenged by the balance of the caregiver/care-recipient relationship. ${ }^{[31]}$ An analysis of the discourse of the professionals we met shows that a paternalistic prescriptive attitude, associated with the wish to bring relief to the patient experiencing the illness, immediately puts the user in a passive mode, from the beginning of the disease. Hence, the patient will not be able to express himself freely concerning his experiences or priorities, placed in an uneven caregiver/care-recipient relationship, where the caregiver is the only expert capable of identifying the patient's expectations, fragilities and needs. The practices of care identified in our results show an irrefutable influence of the caregivers on the patient's ability to actively participate in his own care at the health facility.

\subsection{Supporting the acceptability of changes in nursing practice}

The Intervention aimed at implementing new nursing practices to support patient empowerment must be adapted to the barriers coming under the 3 areas discussed above. The functions of the intervention must be precisely related to the nature of the targeted behavior. The Behavior Change Wheel proposes the type of intervention to be deployed to ensure the best implementation of the change of practices envisaged (see Figure 1). ${ }^{[12]}$

\subsubsection{The need to develop a collective approach to care in- volving concrete tool}

According to Barello, nurses' care is the key to patient engagement, making clear that the commitment is associated with the patient's perception of a positive attitude of health professionals concerning his self-care abilities. This underlines the essential role of the nurses who administer care. ${ }^{[31]}$ Bastas-Bratkic emphasizes that caregivers' motivation to support empowerment can condition the patient's ability to engage and become an actor in his health. ${ }^{[32]}$ In fact, patients tend not to be actively involved in their care when they do not feel they are part of an equal relationship with the caregiver, due to a lack of information on their condition or a partially paternalistic attitude of the health system. ${ }^{[31]}$ In cancer treatment facilities, patient-centered care aimed at supporting empowerment must be done collectively. The care of the patient under this approach should no longer be based on the action and involvement of a single category of staff (coordinating/pivot nurse), as our results confirmed.

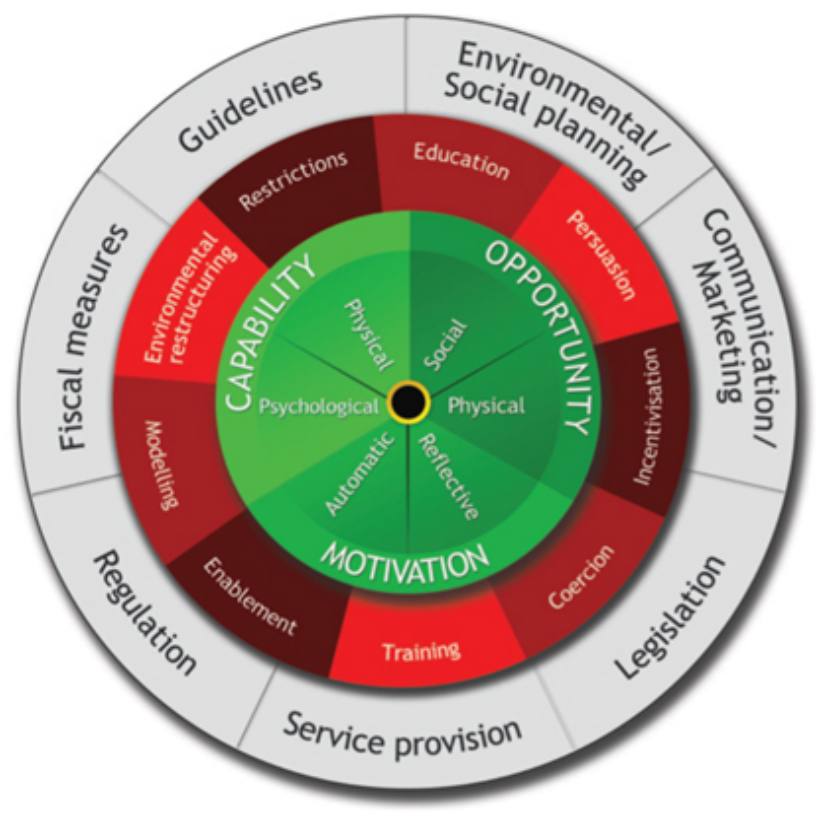

Sources of behavior

Intervention functions

Policy categories

Figure 1. The Behavior Change Wheel

A specific training, including an education component, a persuasion and incentivization component, followed by a practical training phase has been deployed. Indeed, these 4 categories of intervention are those recommended to counter the barriers inherent to Domains 5, 8 and 9 .

For the nurses and physicians included in this study, their beliefs about consequences of patient empowerment and the burden of cancer (TDF domain 5) were perceived as barriers to change in practices of patient-centered care. The educational, persuasion and incentivization component will enable them to understand that changing their representations 
and care can have positive consequences on the patient and themselves.

Social influences (subjective and descriptive norms, TDF domain 9) were also seen as obstacles for these health professionals. An action seeking to provide them with clear information about the patient's wishes and how patient empowerment is supported in other care facilities would allow them to modify their representations and consider different methods of patient care.

With regard to the environmental context and resources (TDF domain 8), the training will shed light on the new recommendations of the Ministry of Health, combining them with the implementation of a tool enabling them to respond positively to these new nursing guidelines. The intervention technique proposed in relation to this theoretical domain served in particular to inform them of how and at what moment to support patient empowerment in current practice.

A device akin to the Patient Activation Measuring tool (developed by Hibbard et al. in 2004) was chosen to enable them to objectively measure the patient's degree of engagement. ${ }^{[33]}$ Nurses will therefore be able to choose and decide on the care to be taken to best support the patient, with appropriate care strategies and assess whether they are beneficial in supporting patient empowerment. The professional could decide on care to be implemented that would best support the patient, incorporating care strategies, subsequently evaluating whether such strategies proved efficient in supporting patient empowerment. A training phase is planned in order to allow staff to take ownership of this change in practice. The caregivers of the study sites could thus play a key role in support of the patient in the course of care in oncology. ${ }^{[8]}$ An implementation of this type of instrument would make it possible to homogenize care by uniting health professionals toward a common goal of supporting patient empowerment along the cancer care pathway. The use of the Patient Activation Measuring tool, combined with their motivation to deploy an appropriate and individualized management approach, will also strengthen them in their role and their nursing expertise.

\subsection{Practical implications}

The French example here is very relevant regarding the difficulty for nurses in changing their care practices. Supporting patients' empowerment and adopting a patient-centered approach is now central in France, unlike other countries, where in oncology in particular, these modes of care have long been in the limbs. ${ }^{[34]}$ According Härter et al., medical education in France devotes little time to teaching about the physicianpatient relationship or to share decision making. France still ranks poorly in terms of patient centered care. ${ }^{[34]}$

Published by Sciedu Press
As highlighted by Curtis et al., whenever we want to improve the quality of care for patients, changing care practices with knowledge from research, it is essential to understand the barriers associated with behavior change and the facilitators of behavior change. This is fundamental to ensuring an achievable, successful, and sustainable deployment. ${ }^{[35]}$

The implementation of new nursing practices is an innovation. Adoption of innovation is subject to various factors such as values, standards, complexity, ability to reinvent, adaptability to organization, relevance to work, additional knowledge and support, among others. ${ }^{[36]}$ The use of a theoretical framework such as TDF and its associated tools allows for the identification of these different factors influencing the successful implementation of new nursing practices. This French example nevertheless shows the need to use a theoretical framework to ensure the best implementation of new practices in the nursing field. Using a theoretical framework such as the TDF linked to the COM-B model and the Behavior Change Wheel to enable the detection of obstacles and facilitators for the implementation of new practices among nurses is a real asset for success in implementing new practice nurses. These tools make it possible to design the intervention to ensure better acceptability of the new practices deployed among nurses' practice. Behavioral change is already a complex intervention in itself. It must therefore be prepared as best as possible to ensure the best conditions for deploying new practices, and to promote their adoption and sustainability.

\subsection{Study limitation}

Despite its limited size, the sample of health professionals included in our qualitative study remains representative of the variety of professional actors most involved in the care of patients treated for cancer in different types of institutions. Given the relative newness of the subject in France, we reached data saturation, and thus did not see the need to expand the sample. Even if these results can be applied to general representations of health professionals in France, it would be useful for further studies to question emerging professions such as Advanced Practice Nurses (once they are employed in large numbers in the field) as well as students in the health sector after an overhaul of medical and paramedical studies can be achieved on a national scale.

\section{Conclusions}

The results of this study illustrate the interconnective issues between the field and ministerial recommendations in France. Earnest work must be undertaken with caregivers to convince them to accept that they no longer control the patients' em- 
powerment but guide and support it. This research shows that nurses in oncology are poorly equipped to implement the guidelines of the new shift in French health policy. The current culture of nursing associated with the organization of care does not seem to be perceived as an alternate approach to working. One can consider that, today, a modification of the treatment practices for patient-centered care in favor of patient empowerment seems somewhat compromised. Moreover, future nurses and physicians trained in this approach will join the ranks of service several years later. To achieve this, TDF linked to the COM-B model has made it possible to think about how to prepare and adapt this change in practice at several sites of cancer treatment. Training adapted to the context to familiarize current nurses with this new form of care is currently being implemented. To succeed, acculturating current nurses to this new form of care, while offering them a tool to objectively assess the level of patient's engagement would undoubtedly foster their involvement in supporting patient's empowerment, while allowing them to evaluate the time required to integrate this type of care.

\section{ACKNOWLEDGEMENTS}

The Direction Generale de l'Offre des Soins (DGOS-French Ministry of Health and Solidarity é) has financially supported this research study.

\section{CONFlicts OF InTEREST Disclosure}

The authors declare they have no conflicts of interest.

\section{REFERENCES}

[1] Ministère des Solidarités et de la Santé. Stratégie nationale de santé 2018-2022 [French Ministry of Health and Solidarity. National Health Strategy 2018-2022]. 2018. Available from: https://solidarites-sante.gouv.fr/IMG/pdf/dos sier_sns_2017_vdefpost-consult.pdf

[2] Ministère des Solidarités et de la santé. Ma santé 2022, un engagement collectif [My Health 2022: A collective commitment] 2018. Available from: https://solidarites-sante.gouv.fr /IMG/pdf/ma_sante_2022_pages_vdef_.pdf

[3] Casalino LP. Disease Management and the Organization of Physician Practice. JAMA [Internet]. 2005 Jan 26; 293(4): 485. PMid: 15671434. https://doi.org/10.1001/jama.293.4.485

[4] Lorig KR, Ritter P, Stewart AL, et al. Chronic disease selfmanagement program: 2-year health status and health care utilization outcomes. Medical care [Internet]. 2001; 39(11): 1217-23. PMid: 11606875. https://doi.org/10.1097/00005650-200111000 $-00008$

[5] Plan cancer 2014- 2019. 2014

[6] Carman KL, Dardess P, Maurer M, et al. Patient And Family Engagement: A Framework For Understanding The Elements And Developing Interventions And Policies. Health Affairs [Internet] 2013; 32(2): 223-31. PMid: 23381514. https://doi.org/10.1 $377 /$ hlthaff.2012.1133

[7] Unicancer. Quelle prise en charge des cancers en 2020? [Internet]. 2016. Available from: http://www.unicancer.fr/patients/ quelle-prise-charge-cancers-2020

[8] Influence of PARAmedical Interventions on Patient ACTivation in the Cancer Care Pathway [Internet]. Available from: https://clinicaltrials.gov/ct2/show/NCT0324034 1 ? id=NCT03240341\&rank=1\&load=cart

[9] Cane J, O'connor D, Michie S. Validation of the theoretical domains framework for use in behaviour change and implementation research [Internet]. 2012 [cited 2019 Apr 5]. PMid: 22530986. https://doi.org/10.1186/1748-5908-7-37

[10] Michie S, Johnston M, Abraham C, et al. Making psychological theory useful for implementing evidence based practice: A consensus approach. Quality and Safety in Health Care. 2005; 14(1): 26-33. PMid: 15692000. https://doi.org/10.1136/qshc. 2004.011155
[11] Atkins L, Francis J, Islam R, et al. A guide to using the Theoretical Domains Framework of behaviour change to investigate implementation problems. Implementation Science [Internet]. 2017; 12(1): 77. PMid: 28637486 . https ://doi.org/10.1186/s13012-017 -0605-9

[12] Michie S, Atkins L, West R. The Behaviour Change Wheel. A guide to designing interventions [Internet]. The Behavior Change Wheel. 2014; 199 p. Available from: http://www. behaviourchangewhe el.com/

[13] Michie S, van Stralen MM, West R. The behaviour change wheel: A new method for characterising and designing behaviour change interventions. Implementation Science [Internet]. 2011 Dec 23 [cited 2017 Nov 20]; 6(1): 42. PMid: 21513547. https://doi.org/10 $.1186 / 1748-5908-6-42$

[14] Glasper A, Rees C. Nursing and Healthcare Research at a Glance. Wiley; 2016. 226 p.

[15] Godin G. Les comportements dans le domaine de la santé: comprendre pour mieux intervenir [Behaviours in the field of health: understanding to better intervene]. Presses de l'Université de Montréal; 2012 [cited 2019 Apr 8]. Available from: https://books . google.fr/books? id=b1dDDwAAQBAJ\&pg=PT 142\&lpg=PT142\&dq=michie+les+domaines+theoriques\&sou $r c e=b l \& o t s=i p 9 \_F p N 4 N 1 \& s i g=A C f U 3 U 34 m 4 j U M$ _sN3xlqUtD cqE0Oc-He3Q\&hl=en\&sa=X\&ved=2ahUKE $w$ jetKX8ksDhAhUPD2 MBHYG8CMEQ6AEwAXoECAgQAQ\#v $=$ onepage $\& q \& f=f$ al se

[16] Phillips CJ, Marshal AP, Chaves NJ, et al. Experiences of using the Theoretical Domains framework across diverse clinical environments: A qualitative study. Journal of Multidisciplinary Healthcare [Internet]. 2015 [cited 2019 Jul 10]; 8: 139-46. PMid: 25834455. https://doi .org/10.2147/JMDH.S78458

[17] Tong A, Sainsbury P, Craig J. Consolidated criteria for reporting qualitative research (COREQ): a 32-item checklist for interviews and focus groups. International Journal for Quality in Health Care. 2007; 19(6): 349. PMid: 17872937. https://doi.org/10.1093/intq $\mathrm{hc} / \mathrm{mzm} 042$

[18] Alexander KE, Brijnath B, Mazza D. Barriers and enablers to delivery of the Healthy Kids Check: an analysis informed by the Theoretical Domains Framework and COM-B model. Implementation Science [Internet]. 2014 Dec 23 [cited 2019 Jul 12]; 9(1): 60. PMid: 24886520. https://doi.org/10.1186/1748-5908-9-60 
[19] Sands J, Wehmeyer M. Self-determination across the life span: independence and choice for people with disabilities. Baltimore MD: Brookes Publishing; 1996. 400 p. Available from: https: //trove.nla.gov.au/work/22026246

[20] Lundahl B, Moleni T, Burke BL, et al. Motivational interviewing in medical care settings: A systematic review and meta-analysis of randomized controlled trials. Patient Education and Counseling [Internet]. 2013; 93(2): 157-68. PMid: 24001658. https: //doi.org/10.1016/j.pec. 2013.07.012

[21] Noordman J, van der Weijden T, van Dulmen S. Communicationrelated behavior change techniques used in face-to-face lifestyle interventions in primary care: A systematic review of the literature. Patient Education and Counseling [Internet]. 2012; 89(2): 227-44. PMid: 22878028. https://doi.org/10.1016/j.pec. 2012.07.006

[22] Mercer SW, Neumann M, Wirtz M, et al. General practitioner empathy, patient enablement, and patient-reported outcomes in primary care in an area of high socio-economic deprivation in Scotland-A pilot prospective study using structural equation modeling. Patient Education and Counseling [Internet]. 2008 Nov; 73(2): 240-5. PMid: 18752916. https://doi.org/10.1016/j.pec.2008.07.022

[23] LEMAY L. L'intervention en soutien à l'empowerment: du discours à la réalité [Speaking in support of empowerment: from speech to reality]. La question occultée du pouvoir entre acteurs au sein des pratiques d'aide. Nouvelles pratiques sociales [Internet]. 2007; 20(1). https ://doi.org/10.7202/016983ar

[24] Gross O. L'engagement des patients au service du système de santé [Patient engagement in the health system]. DOIN. 2017. $168 \mathrm{p}$.

[25] Tran VT, Péan C, Ravaud P. Patients' perspective on how to improve the care of people with chronic conditions in France: a citizen science study within the ComPaRe e-cohort. BMJ Qual Saf [Internet]. 2019 [cited 2019 Jun 24]; 1-12. PMid: 31015376. https://doi.org/10.1136/bmjqs-2018-008593

[26] Longtin Y, Sax H, Leape LL, et al. Patient participation: current knowledge and applicability to patient safety. Mayo Clinic proceedings [Internet]. 2010; 85(1): 53-62. PMid: 20042562. https: //doi.org/10.4065/mcp. 2009.0248

[27] Mougeot F, Robelet M, Rambaud C, et al. L' émergence du patientacteur dans la sécurité des soins en France: une revue narrative de la littérature entre sciences sociales et santé publique [Emergence of the patient-actor in patient safety in France: A narrative review in social sciences and public health]. SFSP santé publique. 2018; 30: 73-81. PMid: 29589694. https://doi.org/10.3917/spub.181.0073
[28] Ninacs WA, Nlnacs WA. Empowerment et service social: approches et enjeux Empowerment et service social: approches et enjeux. 1995 [cited 2018 Apr 26]; 44(441): 69-93. https ://doi .org/10.720 2/706681ar

[29] Pomey MPP, Lebel P. Patient Engagement: The Quebec Path. HealthcarePapers [Internet]. 2016; 16(2): 80-5. https://doi.org/10.1 2927/hcpap. 2017. 24998

[30] Miller WR, Rollnick S. L'entretien motivationnel Aider la personne à engager le changement. In: InterEditi; 2017. 168-72 p.

[31] Barello S, Graffigna G, Pitacco G, et al. An Educational Intervention to Train Professional Nurses in Promoting Patient Engagement: A Pilot Feasibility Study. Frontiers in Psychology [Internet]. 2017; 7. PMid: 28119644. https://doi.org/10.3389/fpsyg. 2016 .02020

[32] Bastas-Bratkic D. Assessing Clinicians' Endorsement of Patient Activation in Health Management. these doctor of nursing practice (DNP) [Internet]. 2017; Available from: http://nursing.fuller ton.edu/programs/pdf/dnp/finalprojects/2017/Bastas -Bratkic_Demetra_DNP_Final_Project_2017.PDF

[33] Hibbard JH, Stockard J, Mahoney ER, et al. Development of the Patient Activation Measure (PAM): Conceptualizing and Measuring Activation in Patients and Consumers. Health Services Research [Internet]. 2004 Aug [cited 2018 Mar 22]; 39(4p1): 1005-26. PMid: 15230939. https://doi.org/10.1111/j.1475-6773.2004.0 $0269 . \mathrm{x}$

[34] Härter M, Moumjid N, Cornuz J, et al. Shared decision making in 2017: International accomplishments in policy, research and implementation. Zeitschrift fur Evidenz, Fortbildung und Qualitat im Gesundheitswesen [Internet]. 2017 Jun [cited 2019 Sep 2]; 123-124, 1-5. PMid: 28546053. https://doi.org/10.1016/j.zefq. 201 7.05 .024

[35] Curtis K, Fry M, Shaban RZ, et al. Translating research findings to clinical nursing practice. Journal of Clinical Nursing. 2017; 26(5-6): 862-72. PMid: 27649522. https://doi.org/10.1111/jocn.1 3586

[36] Newhouse RP. Creating infrastructure supportive of evidence-based nursing practice: Leadership strategies. Worldviews on EvidenceBased Nursing [Internet]. 2007 Mar [cited 2019 Sep 3]; 4(1): 219. PMid: 17355407. https://doi.org/10.1111/j.1741-6787. $2007.00075 . \mathrm{x}$ 